\title{
Processos de Subjetivação em Afro-brasileiros: Anotações para um Estudo
}

\author{
Maria da Consolação André \\ Universidade Brasília
}

\begin{abstract}
RESUMO - O artigo traz reflexões a partir da apresentação de acontecimentos sócio-históricos do sistema escravista percorrendo dois ângulos: sociológico e psicológico. Em relação ao primeiro, por se tratar de uma visão de mundo do que é "ser humano", deu-se ênfase à ideologia do branqueamento para compreender a influência de tal ideologia nos processos de construção das subjetividades de afro-brasileiros, e o segundo, ancorando-o no entendimento de que as relações sociais geram afetos que influem no desenvolvimento biopsicossocial dos envolvidos, afirma que as subjetividades não se fazem ao acaso, não são substâncias em si mesmas, ao contrário, são construídas por meio das várias práticas sociais. Por fim, intenta-se chamar a atenção dos profissionais da Psicologia para refletirem sobre a necessidade de revisão das formas de trabalho com as diversidades populacionais para contribuir no fomento aos estudos dessa temática bem como aos serviços que a área possa oferecer aos indivíduos desse grupo.
\end{abstract}

Palavras-chave: afro-brasileiros; subjetividade; ideologia; branqueamento; psicologia.

\section{Afro-Brazilians Subjectivity Process: Remarks for a Study}

\begin{abstract}
This article aims to contribute for studies and research about questions related to the process of subjectivity of afro-Brazilians. Think over this theme was made throughout the presentation of social and historical facts of the slavery system based on two aspects: sociological and psychological. Firstly, the possibility of someone's view of the world, what does it mean to be a "human being", what are the ideologies that grounded these constructions. Secondly because those subjectivities are not made out of nothing and they are not substances in themselves; on the other side, they are built by many social practices, producing feelings that affect the biopsychosocial potential development of everyone involved with it. Finally, the intention is to call psychologists' attention to review the way so as to ferment studies about this theme and services that this area may offer for individuals of this group
\end{abstract}

Key words: afro-Brazilian; subjectivity; ideology; psychology; whiten.

Os profissionais da Psicologia brasileira têm a importante e longa tarefa de colaborar na construção e divulgação de conhecimento sobre os processos de subjetivação dos afro-brasileiros. Uma referência possível para esse trabalho poderá advir da perspectiva psicossociológica, pois conforme Maisonneuve (1977, p. 2) "sua emergência como ciênciacharneira" poderá auxiliar na compreensão e "explicação da integralidade das condutas humanas concretas". Para a Psicologia, pode-se pensar que a efetivação de tal tarefa possibilitará uma maior produção de conhecimentos sobre esses processos, a partir de investigações acerca das repercussões psíquicas que o sistema escravocrata deixou para as gerações posteriores ao escravismo, posto que tais problemáticas se fazem presentes nas interações entre os diferentes sujeitos, ou seja, nas relações raciais. Algumas reflexões acerca do tema foram produzidas por Andriani (2003), Carone e Bento, (2002), Costa (2004), Reis Filho (2000, 2005) e Ferreira (2000).

Essas reflexões nos lembram que uma das problemáticas nas relações raciais é resultado da ideologia européia que foi

1 Endereço: SHCES 113 Bloco D apto. 408, Brasília, DF, Brasil 70651124.E-mail: consola@terra.com.br disseminada e usada como padrão de vida, um modelo branco que permeou o sistema escravocrata. Essa ideologia permitiu a construção de um imaginário na sociedade brasileira de que o lugar do afro-brasileiro seria de um "estrangeiro", fazendo com que os povos negros se constituíssem à margem, alienados de si, de seus direitos e de sua cultura. Essa alienação é o resultado das experiências discriminatórias vividas pelos afro-brasileiros em razão da herança que essa ideologia deixou no imaginário social.

Objetivou-se, neste artigo, refletir sobre alguns aspectos relativos aos processos de subjetivação dos afro-brasileiros pondo em pauta, particularmente, o registro de acontecimentos sociohistóricos que marcaram a constituição de tais processos, percorrendo dois ângulos: os aspectos sociológicos e os aspectos psicológicos. Em relação ao primeiro, por se tratar de uma visão de mundo, do que é "ser humano", deu-se ênfase à ideologia do branqueamento com o objetivo de compreender a influência de tal ideologia nos processos de construção das subjetividades de afro-brasileiros, e o segundo, direcionando-se as reflexões na busca de uma compreensão de como as imbricações das relações socioculturais presentificam-se na constituição das subjetividades, uma vez que tais constituições não se fazem ao acaso; subjetividades não são substâncias em si mesmas, ao contrário, são construídas por meio das várias práticas sociais, gerando afetos 
e crenças que influenciam os potenciais de desenvolvimento biopsicosocial dos envolvidos.

Tendo em vista os objetivos deste trabalho, registraremos um pouco da história do negro desde a escravidão, considerando os seguintes aspectos: 1) o lugar dos afro-brasileiros no processo de constituição da sociedade, 2) a ideologia do branqueamento a partir da qual essa população foi nomeada como inferior e incapaz e 3) as influências intelectuais, sociais e psicológicas que tal ideologia efetuou no processo de constituição da subjetividade dessas populações bem como suas conseqüências. Tais aspectos serão desdobrados nos cinco subtítulos deste artigo, finalizando-o no sexto subtítulo com uma conclusão.

\section{Questões Preliminares para um Estudo sobre os Processos de Subjetivação}

A ruptura do horizonte simbólico africano, advinda do sistema escravocrata, é um fato de grande relevância que pode nos auxiliar na reflexão sobre algumas questões presentes nos processos de subjetivação dos afro-brasileiros: como a subjetividade é construída a partir das vivências das pessoas, quais são suas transformações, como e por que se transformam. A partir dessas questões pode-se pensar como as continuidades e descontinuidades que surgem durante o desenvolvimento humano podem ser vistas como causadoras/motivadoras dos redirecionamentos que ocorrem no processo de constituição das subjetividades.

No caso dos negros, um desses motivos de redirecionamento se deu pelo tráfico, pela escravização e também pelas tentativas de alcançar a liberdade. Era exigido do escravo uma atitude e ações que pertenciam ao cotidiano do colonizador, do outro, que tanto como alteridade quanto pela ideologia escravocrata, pautada em padrões europeus, era o determinante das relações sociais, ou seja, uma relação de dominador e dominado exercida conforme tal ideologia, mostrando a oposição entre a elite e as populações escravizadas, direcionando o escravo a formatar-se de acordo com os padrões do branco (Meillassoux, 1995). Para o negro, a rebeldia contra a submissão foi, talvez, a mais eloquiente batalha, porque as vivências de repressões física e psíquica tentavam uma interdição do acesso ao seu mundo original, à sua cultura (Carvalho,1996).

Os africanos trazidos para o Brasil pertenciam a etnias diferentes, portadoras de uma diversidade cultural. Ao serem arrancados de suas raízes e vendidos em praça pública como objeto (como peça leiloada), foram separados de seus iguais de forma estratégica para o controle, na tentativa de impedir a organização e a rebeldia dos grupos.

O horizonte simbólico africano foi desacreditado a partir do momento em que não só seus corpos físicos foram seqüestrados, mas também o corpo das práticas sociais que eram produzidas como indicação do sentir, do pensar e do agir no seu mundo cotidiano. Essas formas de conhecimento e representações também eram parte de uma totalidade articulada que eles possuíam. Diante disso, parece relevante registrar o caso dos africanos que, ao serem raptados, sofreram uma separação planejada para que todo tipo de estranheza, desconfiança e desagregação aparecessem (Meillassoux, 1995; Rodrigues, 2000). Klein (2002) anotou que "de fato, foi sugerido que (...) os capitães do tráfico de escravos tentavam misturar os africanos que não falassem a mesma língua, por razões de segurança." (p. 103).

Nesse sentido, pode-se pensar que a ruptura do horizonte simbólico africano é o primeiro fato de grande relevância para a constituição da subjetividade dos afro-brasileiros e, se houver concordância de que todas as experiências de um grupo são uma fonte para a construção de símbolos, deve-se notar que, possivelmente, quando se está num território desconhecido, muito dificilmente os símbolos poderão ser imediatamente reconhecidos pelos outros.

As várias formas de inferiorização propiciaram a exclusão dos afro-brasileiros, a começar pelo aspecto econômico-consumista, pois de acordo com estudos teóricos e estatísticos (Guimarães, 2002; Medeiros, 2004; Paixão, 2003) é essa população a que mais se encontra na classe pobre e; por outro lado, no caso dos afro-brasileiros, a inferiorização dada pela cor, a qual, por ser uma marca, um estigma faz com que essa população não tenha um lugar garantido na sociedade, porque é a partir dessa característica de marca visível que foi simbolizada historicamente, que se aponta, ainda hoje, quem é o negro no Brasil e qual é/não é o seu lugar. Munanga (1988) fortalece essas idéias ao afirmar que

os negros colonizados são oprimidos na sua cor porque também o são como indivíduos e povo. Mas o erro, mitológico, é afirmar a opressão por causa da raça. Os negros não foram colonizados porque são negros, ao contrário, na tomada de suas terras e na expropriação de sua força de trabalho, com vistas á expansão colonial, é que o negro se tornou preto. Houve uma inferiorização econômica, seguida de outra, a epidérmica. (p. 79).

A partir da experiência da Diáspora negra houve algumas perdas e muitas transformações nas manifestações de práticas sociais dos africanos que foram trazidos para o Brasil e dos afro-brasileiros, posteriormente. Hoje em dia várias práticas originárias da africanidade são expressadas regularmente, mas ainda falta tanto um melhor conhecimento quanto uma valorização das mesmas como afirmação do protagonismo dessa população como parte do coletivo que construiu a sociedade brasileira, ao invés do cunho folcloresco adotado por vários seguimentos.

A saída, muitas vezes, é viver na marginalidade que, mesmo sendo uma forma de vida fora do centro, da cena principal, pode ser vista como um modo de inventar-se/construir-se nas margens, como os quilombos mostraram - o que não é de todo negativo. O dilema é que muitos, por serem negros, se tornaram - como se tornam até hoje - desacreditados, apartados ${ }^{2}$ socialmente e, às vezes, desviantes.

Para se conhecer quais podem ser as repercussões psíquicas das experiências de apartação social, se faz importante refletir sobre algumas características significativas da exclusão que são apontadas em vários estudos sociológicos, psicológicos, políticos e econômicos e neles aparecem evidenciadas as ex-

2 Usamos, neste trabalho, derivações do termo apartação social que foi utilizado por Buarque (1993) e definido como um processo no qual o outro é nomeado como um ser à parte, designando um fenômeno de separação desse outro que é visto como desigual, não semelhante, expulso dos meios de consumo, dos bens e, principalmente, do gênero humano, caracterizando o que se compreende por intolerância social. 
periências dos afro-brasileiros (Martins, 1997; Sawaia, 2001). Fortalecidas pelas atitudes racistas da discriminação pela cor tais caracterizações têm se tornado, historicamente, um fator que pode gerar o auto-isolamento, sofrimento psíquico, baixa auto-estima, dificultando mais ainda a construção de uma identidade e, portanto, a constituição de subjetividades.

Tajfell (1982) acreditava que os processos de categorização, comparação e diferenciação social são aspectos relevantes na formação da identidade social e que essas atribuições podem influenciar negativamente essa construção. $\mathrm{O}$ autor cita os estereótipos e os define como "a atribuição de características psicológicas gerais a grandes grupos humanos” (p. 289).

Seve (1975), no livro Marxisme et Théorie de la Personalité, opinou que para a idéia simplista causaria incômodo supor que não se deve opor a forma política e a forma psicológica de abordar um problema, pois é freqüente que sejam precisamente as lutas políticas que, por si mesmas, colocam, inexoravelmente, problemas de ordem psicológica. Prosseguindo em sua sustentação, esse filósofo registrou que "vários problemas de ordem política consistem, pelo menos em parte, num problema psicológico que se coloca a milhões de homens" e para ele "a batalha política não pode ser levada a cabo até o fim, nem mesmo sequer, em certos casos, ser desencadeada, a não ser na medida em que possa socorrer-se de uma psicologia realmente cientifica" (p. 21).

Tratar das questões dos afro-brasileiros exige um olhar para muitos dos aspectos dos problemas sociais do Brasil. Envolve as muitas psicologias (ver, por exemplo, Dorsch, Hacker \& Stapf, 2001), tais como se apresenta esquematicamente em seguida alguns exemplos de assuntos significativos para algumas disciplinas da psicologia:

a) Psicologia dos grupos: o bode expiatório, o líder (Freud (1921/1980) - Psicologia de grupo), a vitimização, o conformismo;

b) Psicologia da cultura, do lazer: as contribuições do negro tais como a capoeira, o samba, samba-de-roda, a congada, etc;

c) Psicologia da identidade, da personalidade do escravo e das gerações atuais: herança intergeracional;

d) Psicologia das emoções, dos sentimentos: a culpa, a inferioridade, a vergonha, o banzo;

e) Psicologia das marginalidades: a vida nos quilombos, favelas, periferias, etc.;

f) Psicologia social: a representação social do negro.

\section{Processos de Subjetivação e a Invisibilidade Pública: Herança do Sistema Escravocrata}

Os afro-brasileiros tornaram-se invisíveis simbólica e socialmente ao serem considerados como elementos desinteressantes para o progresso da nação, e tal fato configurou uma experiência de vida na marginalidade, a qual pode ser pensada como uma forma de vida fora do centro, da cena principal, como se lê em Selosse (1997).

Anotar como as tramas dessa invisibilidade ocorreram é um ponto importante para os objetivos desse artigo, principalmente se a atenção se voltar para uma contradição: os africanos e seus descendentes no Brasil, porque se tornaram a primeira mão-de-obra para o progresso econômico, deveriam ser considerados protagonistas de primeira linha nesse empre- endimento. No entanto aconteceu o contrário, pois os africanos e os crioulos/afro-brasileiros (nascidos no Brasil) sofreram as conseqüências dessa "nova significação imaginária": o sistema escravista, instituído como "(...) uma nova maneira de se viver para a sociedade, de se ver e de agir (...) articulada de maneira antagônica e não simétrica" (Castoriadis, 1982, p. 186). A elite criou regras, regimentos, decretos que foram aceitos pela sociedade em geral, os quais receberam significações e sentidos e passaram a fazer parte do imaginário social com repercussões negativas para a população negra até os dias atuais.

Para Castoriadis (1982)

falamos de imaginário quando queremos falar de alguma coisa "inventada" - quer se trate de uma invenção absoluta ("uma historia inventada em todas as suas partes”), ou de um deslizamento, de um deslocamento de sentido, onde símbolos já disponíveis são investidos de outras significações normais ou canônicas. (p. 154).

No entendimento do autor, "a dominação do imaginário é igualmente clara no que se refere ao lugar dos homens, em todos os níveis da estrutura produtiva e econômica". E prossegue registrando que "esta significação é estritamente ligada às outras significações imaginárias centrais da sociedade, especialmente a definição de suas necessidades e sua imagem do mundo." (p. 189).

Munanga (1988) também é favorável ao debate dessas questões, pois acredita que foram as formas de vida constituídas no imaginário social que negaram a escuta, a visibilidade e a valorização dessas populações, colocando os afro-brasileiros para fora do centro dessas sociedades, contribuindo para a fabricação de uma identidade negativa - do ser africano, do ser crioulo - fortalecendo, nesse caso, a exclusão/inclusão daqueles que apresentavam a marca da cor, o que aparece registrado na idéia nacionalista do branqueamento.

A invisibilização dos afro-brasileiros pode ser confirmada nas referências ao mito da democracia racial que aparece coberto pelo manto da mestiçagem defendido por Freyre (1993/2003), um dos divulgadores desse mito, pois para ele "as boas relações" entre a casa grande e a senzala, a "mistura racial" dariam a indistinção de cor/raça no Brasil. De acordo com esse pensamento, afirmou Telles (2003) que Brasil se tornaria "um país moreno". Essa "cor" está registrada como uma categoria presente em alguns censos no Brasil.

Acredita-se que existem dois aspectos na questão da invisibilidade: 1) o lado invisível do mundo dos afro-brasileiros, afirmado por teorias que atestavam sua inferioridade tomando como parâmetro a população branca e que foram difundidas por vários cientistas em meados dos séculos XIX e $\mathrm{XX}^{3}$ e 2) a visibilidade "oficial" desse mundo dos negros que é percebido por meio dos estereótipos, fantasias, preconceitos, atitudes, crenças sobre o africano e os afro-brasileiros.

Historicamente, os africanos, e conseqüentemente os afrobrasileiros, foram identificados como gente do lado de lá, o

3 Em vários autores que consultamos a respeito de tais teorias (Coimbra, 2001; Meillassoux, 1995; Santos, 2002) encontramos referencias a teóricos e cientistas como Gobineau (1853), Le Bon (1894), Galton (1869), Nina Rodrigues, R. (1904/2004). 
estrangeiro, o outro. Essa estranheza deu-se por meio da discriminação racial. Nascimento (2003, p. 47) argumentou que "a noção de 'raça', firmemente embutida na hierarquia da cor que, mesmo sendo carente de realidade biológica, exerce uma função social de forte impacto concreto sobre a vida real". Trata-se do fenômeno de raça socialmente construído"'. A partir dessa premissa, o mundo dos brancos foi considerado superior, ideal e deveria ser buscado por todos. No caso dos negros, tal busca passou a ser constante e sofrida com inúmeras tentativas de encontrar um lugar de igualdade pautado na simetria de oportunidades, na equidade. Isso não ocorre, pois esse lugar sendo racializado conforme a ideologia afirmava a inferiorização do negro.

Tomando como indicativo a ótica socioeconômica e política, pode-se identificar quem é afro-brasileiro e constata-se que os espaços de poder, de status são ocupados, na grande maioria, por uma mesma população: a branca. Hasenbalg (1998, p. 237) ressalta que o fato de confundir-se "as misturas raciais no plano biológico com as interações raciais no sentido socioeconômico" pode ocasionar uma grande ilusão, que às vezes é aceita e valorizada, ou seja, de que essa interação biológica é supostamente vista como democracia racial pelo alto grau de miscigenação, fortalecendo a ideologia do branqueamento, miscigenação que parece perdurar no imaginário da sociedade. Outra crença é de que no nível político e socioeconômico haja uma democracia racial e que "é o negro que não está preparado para atingi-lo". Caso isso seja verdade, porque será que ele não está preparado?

Entendendo que a democracia racial enquanto política e ideologia racistas acentua a diversidade de interesse entre os vários segmentos dominados. Observa-se que o privilégio econômico, político, ideológico e sociocultural do branco está imbricado, historicamente, com a divisão social e funcional que dá acesso ao trabalho, à educação, à saúde, ao lazer. Tais acontecimentos têm feito com que as mudanças ou transformações, no plano estrutural da sociedade e no plano de distribuição de renda e de recursos, se apresentem como processos que possibilitam, em sua maior parte, conquistas ao segmento branco.

\section{A Visibilidade para os Afro-Brasileiros: Começando pelos Quilombos}

Quilombos, Mocambos, Comunidades Negras Rurais ou Terra de Pretos, Favelados, Moradores das Periferias. Assim são conhecidos os grupos/territórios ocupados por pessoas de origem negra que vivem em agrupamentos afastados dos centros urbanos.

As comunidades de ex-escravos e de descendentes de quilombolas estão espalhadas por inúmeros estados da nação e, juntamente com outros territórios (favelas e periferias), estão espalhados pelas faixas de pobreza nas várias localidades do Brasil, "incluídos" nos moldes da globalização, mas apartados aos olhos do coletivo que mantém os resquícios do que foi construído como imaginário social sobre o negro.

Acredita-se que para dar visibilidade aos negros é necessário trazer à luz a invisibilidade. Uma das formas de buscar tal visibilização tem sido efetivada por meio dos registros dessas populações pela utilização de narrativas e/ou levantamento de documentações em algumas regiões como Rio das Rãs, Bahia
(Carvalho, 1996) e Cafundó, São Paulo (Vogt \& Fry, 1996), O negro no Pará (Salles, 1971), na discussão sobre as formas de vida dos quilombos como bem divulgou Moura (1988, 2001), entre outros. No que concerne à geografia, podemos consultar os trabalhos de Anjos (2000, 2006) em que o autor fez o mapeamento de comunidades remanescentes de antigos quilombos no Brasil.

Como exemplo dessas práticas, também Reis e Gomes (1996) organizaram um estudo historiográfico sobre os quilombos no Brasil, apresentando uma variedade de interpretações, por se tratar de um material escrito por vários autores. O material tentou cobrir todo o território nacional, desde o Rio Grande do Sul passando por Minas Gerais, São Paulo, Rio de Janeiro, Bahia, Maranhão, Mato Grosso, Goiás e até o Pará. Foram utilizadas fontes orais, tendo os descendentes de escravos como relatores, e também fontes documentais, confirmando que geograficamente os quilombos existem em grande número e com uma enorme riqueza, tanto nos aspectos naturais quanto nos culturais. Conforme o registro dos autores, os quilombos apresentavam uma forma de vida peculiar pautada no comunitarismo, instituidor de modos específicos de governo e de relações no grupo como um todo, o que tem reflexões psicológicas na construção da subjetividade dos quilombolas e de seus descendentes. Um dos motivos da formação dos quilombos se encontra nessas formas de violência a que muitos queriam, cada vez mais, fugir. A quilombagem pode ser vista como tentativa de resistência, de construção de uma identidade positivada e a busca da emancipação.

Partindo da leitura das obras de Anjos (2000, 2006); Campos (2005); Carvalho (1996); Chaloub (1996); Moura (1988, 2001); Reis e Gomes (2003); Salles (1971), Vogt e Fry (1996), confirma-se que há uma relevância em registrar a região, a territorialidade como lugar de referência das constituições das subjetividades, ainda que seja por meio de uma vivência marginal. Na perspectiva da Psicossociologia, tais registros se tornam significativos para a reflexão acerca de qual é esse espaço ocupado e como foi (é) incorporado de acordo com três aspectos - um espacial, outro psicológico e um terceiro como lugar de construção dessas subjetividades. No primeiro aspecto, acreditamos que a busca de um lugar, um território no qual se sentissem referenciados, seguros, abrigados, onde pudessem construir uma vida, tenha sido a primeira meta tanto para os escravos fugidos quanto para aqueles que por interesse se juntassem a eles. O segundo aspecto perpassa o primeiro, pois se encontra interligado às questões já citadas acrescidas de outras, tais como: quais as emoções, os afetos, as crenças, as esperanças e sonhos que foram mobilizados no empreendimento. O terceiro como local de construções sociais, políticas, culturais e afetivas que se imbricam no desenvolvimento do ser humano, como se vê nos registros sobre alguns desses territórios no Brasil e também no exterior, pois configuram o que se denomina como identidade cultural.

Pelas referências toma-se conhecimento que o afro-brasileiro morador dessas regiões foi estigmatizado por meio da imagem do fugitivo e, muitas vezes, como indivíduo perigoso pelo fato de ter sido ousado na busca de sua liberdade, contrariando a ordem oficial de submissão. Em alguns registros (Coimbra, 2001; Neves, 2002; Pinaud, 1987; Reis \& Gomes, 1996; Vogt \& Fry, 1996) constata-se que não foram todos os afro-brasileiros que aceitaram as imposições do coloni- 
zador. Ao fugir, criar os quilombos e outras formas de vida comunitária, demonstraram o seu descontentamento com a situação, passando por isso, principalmente para os senhores de engenho, a imagem de um rebelde, um transgressor desvalorizado, um desviante. Enquanto para ele mesmo, a transgressão revelava-se como possibilidade de reencontro com sua dignidade, de preservação de sua ancestralidade.

Das vivências tradicionais africanas restaram algumas manifestações, tais como a capoeira e o samba-de-roda, que eram desenvolvidas como meio de divertimento, mas também como forma de expressar e comunicar a sua história por meio de linguagens diversas que faziam parte de suas origens. Outra importante manifestação é a religião, a qual pode ser considerada como um locus essencial para a manutenção de algumas referências da identidade africana.

Isso permitiu que, mesmo nas descontinuidades, alguns hábitos e comportamentos expressivos da cultura negra fossem exercitados, possibilitando manter particularidades do ser negro vistos na permanência de traços importantes e ricos do que é básico das culturas africanas e posteriormente a cultura dos afro-brasileiros, com seus códigos, valores e crenças, os quais são muitas vezes tratados pela sociedade em geral apenas como "primitivas" ou "manifestação folclórica".

Nesse sentido, o Quilombo, as Favelas, as Periferias podem ser considerados modelos de resistência/resiliência ${ }^{4}$ (Campos, 2005; Carvalho, 1996; Chalhoub, 1996; Coimbra, 1995; Moura, 1989; Munanga, 1988) e lugar de exercício da cidadania, onde acontecem as formas de vida especificas dessas populações. Esses fatos contribuíram para que alguns traços da identidade originária e sociocultural continuassem a existir. Por isso podem também ser vistos como lugares de registro de memórias e de construções históricas. Conforme Castoriadis (1982, p. 177) "o mundo social é cada vez constituído e articulado em função de um sistema de (...) significações (...) que uma vez constituídas (...) existem na forma do que chamamos o imaginário efetivo (ou o imaginado).”

Por meio dessas obras pôde-se verificar, principalmente nas áreas da Sociologia, Antropologia e História, que um desses imaginários efetivos sobre o ser negro no Brasil diz respeito à ideologia do embranquecimento, pautada principalmente em teorias biológicas e que foi pensada como solução para o problema do negro, o que do nosso ponto de vista só serviu para fortalecer as já existentes dificuldades de inserção sociopolítica dos afro-brasileiros.

Os processos de embranquecimento e miscigenação são construções ideológicas, e como tais devem ser contempladas em discussões que possam nos auxiliar na compreensão de como e quanto os acontecimentos históricos acarretaram e acarretam um dano psíquico aos corpos coletivos, e as

4 O termo resistência utilizado neste trabalho diz respeito a uma ação de oposição e recusa aos preceitos que as regras da escravização imputavam aos negros, o que em nosso entendimento, liga-se às questões do social.

Em relação ao termo resiliência adotaremos explicações que remetam ao caráter psicológico, uma vez que o mesmo é também utilizado em outras áreas tais como: Engenharia, Ecologia e Física. Para o nosso interesse, o significado do termo é aquele que o relaciona a adaptação, registrando que ocorrem variações individuais de respostas a fatores de risco (Rutter, 1996), denotando questões do desenvolvimento psicológico. modalidades - em nosso caso, o sistema escravocrata - com as quais a violência contribuiu para a configuração das subjetividades.

Do ponto de vista dos objetivos deste artigo, este poderá ser um assunto, um mote fundamental para o trabalho dos profissionais da Psicologia, pois ao se buscar conhecer e compreender quais são as possíveis repercussões psicossociais da herança do sistema escravocrata nos processos de subjetivação dos afro-brasileiros, poder-se-á perspectivar novas formas de abordar a questão bem como a construção e aplicação de instrumentos que possam contribuir para o aparecimento de novas visões sobre essa população.

\section{O Projeto de Embranquecimento: Maquínica da Exclusão dos Afro-Brasileiros}

A miscigenação é um fenômeno que acontece regularmente quando há o encontro e vida social comum entre duas raças ou povos. Esse fato foi usado pela propaganda da democracia racial existente no Brasil, que fazia da abolição da diferença, pela miscigenação, da ilusão do embranquecimento, a possibilidade futura de dirimir os problemas raciais.

Os fundamentos da ideologia racial foram elaborados pela elite brasileira a partir do século XIX e meados do século $\mathrm{XX}$, tendo como um dos princípios, ainda que não declaradamente, dividir negros e mestiços pela alienação dos processos de identidade de ambos (Guimarães, 1999; Hasenbalg, 1998).

Há, nessa questão, um aspecto contraditório e, no entanto, foi por essa via que a miscigenação se deu no caso brasileiro. Tal aspecto liga-se a três formas por meio das quais a miscigenação se tornou um fato. Uma delas foi pela violência sexual, dos estupros cometidos pelos senhores de engenhos. A outra ocorreu por meio dos concubinatos, pois os casamentos inter-raciais não eram permitidos (ambas ainda no período da escravidão) e uma terceira que seria pela chegada dos imigrantes e "a permissão" de casamentos entre os diferentes grupos. Com essa ocorrência o que se seguiu historicamente foi a idéia de que "os mulatos" nascidos desses encontros teriam o passaporte para o aparecimento no mundo branco, no futuro, correspondendo dessa forma à ideologia do embranquecimento, desejo daqueles que estavam no poder e da sociedade em geral; e, para o negro, a esperança, o sonho, a ilusão de que os seus herdeiros talvez pudessem ser incluídos como parte da sociedade.

Como exemplo dessa segunda forma de miscigenação, temos a história de Francisca da Silva (Furtado, 2003), nascida entre 1731 e 1735, parda, filha de Maria da Costa (escrava negra) e de Caetano de Sá (homem branco que, de acordo com os registros dessa historiadora, não era o seu dono). Utilizaram-se alguns registros dessa biografia, porque entendeu-se que a história de Chica da Silva é uma confirmação da existência de ideologias que supostamente promoveriam a inclusão dos afro-brasileiros no mundo dos brancos. Conhecida como Chica da Silva, foi concubina de João Fernandes de Oliveira, contratador de Diamantes, com quem teve vários filhos. Ao adotar os hábitos, valores e crenças da camada da sociedade dos brancos, a personagem obteve acessos a alguns momentos/eventos desse grupo, mas jamais foi totalmente inserida, o que se verifica pelo fato de 
que não podia documentar o seu casamento, assinando o sobrenome Oliveira.

Furtado (2003) registrou uma questão importante sobre a ação de Chica no que se refere a construção de identidades, bem como a importância de se conhecer e compreender os processos de subjetivação a partir dos contextos. Mudando o seu nome para Francisca da Silva Oliveira começou uma nova jornada, uma nova vida, buscando uma afirmação de si mesma. É significativo observar como o outro - o contratador João Fernandes de Oliveira - teve um papel fundamental para que Chica pudesse concretizar o seu projeto de inserção na sociedade. A pergunta que aparece é por que isso ocorreu e encontra-se como resposta que, a identificação da personagem com o status do contratador, que era um representante oficial da ideologia branca da época, muito contribuiu para que Chica "ascendesse" a um outro patamar da sociedade em que viveu, o que não significa que tenha conquistado efetivamente a sua inclusão social, como se verá mais à frente neste artigo nos registros do processo de "genere" de um de seus filhos, e também permite que se pense em possíveis vivências de conflito de identidade por parte da personagem, pois como afirmou Reis Filho (2000, p. 21) $)^{5}$ revelando a sua fantasia "ninguém atravessa o arco-íris".

De acordo com Johnson (1997), ideologia é um conjunto de crenças, valores e atitudes culturais que servem de base e, por isso, justificam até certo ponto e tornam legítimos o status quo ou movimentos para mudá-lo.

No imaginário coletivo do brasileiro, o país é conhecido como mestiço, o que de novo reforça a ideologia e o mito da democracia racial que, na verdade, tinha a intenção de instituir uma identidade nacional, pensada como possível após algumas gerações, por meio do embranquecimento da população brasileira. Prosseguindo com o suporte de Johnson (1997), podemos registrar que,

do ponto de vista marxista, a maioria das ideologias reflete os interesses de grupos dominantes, como maneira de perpetuar sua dominação e privilégios. Este fato é especialmente verdadeiro no caso de sistemas opressivos, que requerem justificação detalhada para que continuem a existir. (p. 126).

É importante lembrar da existência de uma aliança entre o que a ideologia da época postulava e as possibilidades científicas e sociais para concretizar o que era ideologizado. Sobre esta questão, Santos (2003, p. 16) registrou que "para a produção do ser negro" foram constituídas teses elaboradas a partir da biologia; teorias sobre a transformação da cor dos indivíduos em uma fase visível de suas essências. Nessa produção foi considerada a existência de uma hierarquia temporal e antropológica na história, houve uma "constatação" de que nos diferentes grupos - asiáticos, europeus, africanos - o tamanho dos crânios e cérebros determinava o caráter do individuo, criando inclusive um código legal que asseverava o pertencimento de cada criminoso a um determinado grupo/raça. Corroborou, também, um fortalecimento

5 O autor falou de uma fantasia recorrente de sua infância, o que levou a dar o titulo de sua dissertação de mestrado e, posteriormente, o titulo do livro que citamos: Ninguém atravessa o arco-íris: um estudo sobre negros. das idéias de que a cor é um valor, é um símbolo próprio, a idéia de que haveria uma sexualidade para cada grupo/raça, bem como diferenças de humor, potencialidades cognitivas, entre outros aspectos da psicologia humana e, em especial, os aspectos negativos recairiam na nomeada raça negra, confirmando o que é "ser negro".

Dando ênfase a essas questões, citamos partes do processo de "genere" de Simão Pires Sardinha, filho mais velho de Chica da Silva com Manuel Pires Sardinha, seu proprietário. Simão teve interesse em ser cavaleiro da Ordem de Cristo, instituição existente no século XVII na qual, inicialmente, só ingressavam aqueles que fossem nobres de nascimento; depois mudaram-se os estatutos e pessoas de grupos/setores financeiros e comerciais que haviam ascendido na escala social começaram a ser aceitas. Para que ocorresse a aceitação era preciso saber "o lugar que cada indivíduo ocupava na sociedade (o que) se baseava na linhagem; assim as honras ou mazelas derivadas do nascimento eram transmitidas de geração para geração" (Furtado, 2003, p. 58).

Simão Pires Sardinha estava fora dos critérios para a aceitação porque era filho de uma relação ilegítima entre um senhor e sua escrava. Como fazer se ele possuía "o obstáculo quase intransponível para a concessão do hábito (que era) a descendência escrava, já que ilegitimidade e mulatismo eram 'defeitos' passíveis de dispensa real.' (Furtado, 2003, p. 59). O rapaz utilizou estratégias que escondessem suas origens como descendente de escravo e de seu nascimento, arrolando falsas testemunhas para os depoimentos sobre sua origem.

Partindo dessa estratégia, reelaborou toda a sua história, subtraindo "as imperfeições" que possuía por herança. Consta que o uso dessas testemunhas e de suas "evasivas" durante os depoimentos foram suficientes para a conquista do posto. Para a nossa reflexão nos interessa registrar a citação de um dos depoentes - Baltazar Gonçalves de Carvalho - no processo (Furtado, 2003), porque a mesma ilustra a temática sobre o embranquecimento como ideologia experienciada por todos os membros da sociedade, desde as mais antigas épocas até a atual e nesse caso podemos corroborá-la utilizando um documento que mostra a importância que era dada à herança marcada pela condição social e principalmente pela cor da pele. Em seu depoimento, Baltazar Gonçalves de Carvalho disse que Chica era

filha legitima do capitão dos auxiliares Antonio Caetano
de Sá e de Maria da Costa, que possuíam muitos cabedais
e uma copiosa escravatura, sendo esta de cor parda e, por
conseqüência, sua filha, mãe do habilitado. Já neste, fica
em terceiro ou quarto grau, porém vivendo todos com uma
excelente reputação e à luz da nobreza, com muita riqueza e
fazendo a primeira figura naquele continente, visitados das
(sic) primeiras pessoas. (p. 63 ).

Ressalta-se aqui o processo de introjeção dos padrões da ideologia que se assenta nos valores, crenças e hábitos dos brancos. Portanto, quem possuía a marca da cor por origem e descendência não poderia ingressar nos grupos da elite e do poder a não ser que fizessem como Simão Pires Sardinha fez, ou seja, negar primeiro a sua herança de marca. Quais seriam as conseqüências de tudo isso? 
Em relação ao projeto do embranquecimento, pode-se pensar que tal questionamento seria respondido pela constatação de que apesar desse projeto ter fracassado em sua concepção básica, que era o embranquecimento físico (e isso seria uma suposição, posto que teriam que se levar em conta as questões genéticas intergeracionais, que dizem respeito aos genes recessivos), o que se pode inferir é se não perdura um projeto de embranquecimento psicológico, intelectual, social perpassado pelas injustas e antigas classificações socioeconômicas e biológicas. Esse é um ponto também inserido nas discussões sobre democracia racial, inclusão/exclusão, pois no seu princípio, a democracia racial deveria garantir um lugar sociocultural para todos. No caso da população negra, a luta é para sair da margem e dar-se a conhecer como participante real na construção da sociedade e não apenas como entidade folclórica, exótica, como se vê nas datas comemorativas. Trata-se de uma luta para que, de fato, a sua contribuição na formação da cultura brasileira seja visualizada e valorizada.

Furtado (2003) nos auxiliou na reposta ao registrar que apesar dos esforços de Chica da Silva para tentar garantir uma ascensão social de seus filhos, o destino dos mesmos foi marcado por situações nas quais a fortuna e a ascendência paterna lhe foram favoráveis. Em outras foi a cor e a marca da escravidão, herdadas da mãe, que serviram para o impedimento de suas inserções no mundo branco. A autora afirmou que, para Chica da Silva

acima de tudo, sua trajetória revela a tentativa do branqueamento como forma de se inserirem mais favoravelmente na sociedade preconceituosa que se instituía no Brasil e que, longe de ser uma democracia racial, apresentava mecanismos de exclusão baseados na cor, na raça e na condição de nascimento. (p. 246).

Tais questões foram anotadas por dois motivos: primeiro pelo fato de que o que era tido como minoria até pouco tempo atrás hoje está se concretizando em maioria e nos faz lembrar que esse discurso é também ideológico; segundo porque acreditamos que exista uma diferença entre achar que os afro-brasileiros fazem parte da sociedade somente pelo lado folclórico/exótico e o discurso/projeto de incluí-lo como agente efetivo da cultura e da mesma sociedade, o que permite, no máximo, que ele permaneça à margem da história. Ambos não ajudaram (nem têm ajudado) a população negra a obter a categoria de cidadã.

\section{A Subjetivação na Sociedade de Consumo: Inclusão e Exclusão}

Na introdução do livro Exclusão Social e a Nova Desigualdade (Martins, 1997) há uma discussão que nos pareceu atual e real ${ }^{6}$, dando ênfase a uma necessária indicação sobre qual será a área em que o tema da exclusão é colocado. Na perspectiva de Martins, a exclusão poderá ser vista sob a ótica

6 Real nessa parte do trabalho terá dois usos: o primeiro será o de realizações, de concretude. O outro é um contraponto a romantizações de temas complexos existentes nas problemáticas que envolvam diferentes populações, como é o caso da população negra. economicista, sociológica e política. Mesmo orientando-se por uma visão sociológica, o autor nos lembra que a temática está posta em um sistema que engloba essas e outras áreas. Para o autor, “(...) rigorosamente falando não existe exclusão; existe contradição, existem vítimas de processos sociais, políticos e econômicos excludentes". (p. 14). A reflexão do autor acima citado lembra as modalidades de vida que na nossa sociedade atual se caracterizam por apresentar uma duplicidade, dois mundos excludentes entre si, embora parecidos na forma. Como isso é possível? Pelo fato de que são oferecidas "as mesmas mercadorias", "as mesmas idéias individualistas, competitivas". Então o que é diferente? A assimetria de oportunidades, apesar de haver uma divulgação pelos discursos políticos, pela mídia e pelo imaginário coletivo de que ocorre o contrário, ou seja, de que vivemos numa sociedade plural, "uma aldeia global" que dá as mesmas oportunidades para todos, pois somos todos iguais (p. 22).

Por contradição, esse processo social de exclusão acarreta uma inclusão ideológica (conforme Furtado, 2003) instaurada no imaginário da sociedade em geral, que é a inclusão para o consumo propalada pela mídia e que cria a ilusão do pertencimento. No entanto, a inclusão social continua inexistente porque tais pessoas - os afro-brasileiros, em sua maioria - não participam da produção desse trabalho, produto imaterial, que são as ações que levam as pessoas ao exercício consumista. Tem-se informação, por exemplo, que na favela existem antenas parabólicas, carros e outros bens de consumo semelhantes aos que os ricos possuem e que são divulgados pela ideologia de mercado, e nem isso faz com que algumas dessas pessoas que sejam negras (na favela vivem pessoas de todas as cores) sejam colocadas como efetivamente pertencentes à sociedade. Nessa conformação, a contradição do discurso sobre igualdade se dá pelo fato de que não existe lugar sociopolítico-econômico para todos e as formas de buscar esses bens acabam sendo, muitas vezes, as mais degradantes possíveis, instaurando-se o desvio, a delinqüência, o que só aumenta o distanciamento da inclusão social. Uma outra face desse tema, e até mais delicada, é a de que nos processos de exclusão ocorre um outro, de reinclusão, em situações precárias, marginais, como vemos em relação à pobreza, ao desemprego, cujos tipos e faixas se ampliam cada vez mais. Martins (1997) comenta que há uma "nova exclusão, que atribui ao excluído um lugar de carência material, e sobretudo o fato de "ser aquele que não é reconhecido como sujeito, que é estigmatizado, considerado nefasto e perigoso à sociedade" (p. 16) e que há uma necessidade desse reconhecimento, tanto da parte de quem sofre a apartação quanto da parte daquele que atua como apartador.

\section{(In)Conclusão}

O que fazer com isso? Para uma boa compreensão da subjetividade e identidade da população negra, entendemos que serão necessários os seguintes passos: contribuir para um exercício de desconstrução das visões sobre o negro dadas pela herança do passado escravista, da ideologia do branqueamento e da realidade contemporânea de apartação social a que esse grupo tem sido submetido. Como profissionais da Psicologia, deve-se pensar que somente por meio 
de mudanças dessas visões é que poderão colaborar para que possíveis transformações pessoais e coletivas ocorram, uma vez que antigas formas de vida que estão arraigadas no imaginário da sociedade contribuem para uma divisão desigual e negativa dos indivíduos e de grupos portadores de traços que historicamente têm sido usados como determinantes de características psicológicas, estéticas, morais, intelectuais e sociais.

Parece ser relevante primeiro pesquisar mais sobre quais são as repercussões psíquicas que podem ser consideradas advindas da herança do sistema escravocrata: sentimentos de inferioridade, uma baixa auto-estima, sentimento de vergonha, de culpa, de humilhação, medo que se faz presente nos processos de desenvolvimento psicológico dessas populações. E segundo, confirmando-se que tais acontecimentos poderão ser os geradores de sofrimento psíquico, de dificuldades de se afirmar como sujeito potente, humanizado, pertencente à sociedade, caberá aos profissionais da psicologia maximizar as ações que permitam o trabalho com esses sujeitos.

Politzer (1965), no seu livro Psicologia Concreta, opinou que caberia à Psicologia ocupar-se da vida humana propriamente dita, do cotidiano, da vida psicológica, ao que denominou "vida dramática". Para ele, o objeto da Psicologia deverá ser entendido como o conjunto de acontecimentos que ocorrem desde o nascimento até a morte. Há na sua compreensão uma necessidade de que tal área se dirija a um homem concreto, porque será na experiência concreta que o mesmo mostrará o seu drama, nas variadas formas de conduta.

Baró (1996), no seu artigo O papel do psicólogo, registrou que esse papel deverá ser "definido em função das circunstâncias concretas da população a que deve atender" (p. 7). $\mathrm{O}$ autor referiu-se às situações problemáticas vividas pelos povos centro-americanos caracterizando-as em três aspectos: "(a) a injustiça estrutural, (b) as guerras ou quase-guerras revolucionarias e (c) a perda da soberania nacional" (p. 7). Apesar de que, no Brasil, as ocorrências citadas nos itens (b) e (c) não têm se apresentado atualmente, pode-se atentar ao primeiro que aparece em índices elevados para as populações das periferias do Brasil, nas quais grande parte dos afro-brasileiros estão inseridos, configurando uma situação específica desse grupo. Agregue-se a isso a história dos afro-brasileiros perpassada pela herança identificadora do "lugar" que lhes caberia por serem herdeiros do regime escravista. Nesse sentido, há que se concordar com as reflexões de Baró (1996) quando o autor disse que conforme a variação das circunstâncias e, portanto, da clientela, deve-se mudar os modelos conceituais e/ou práxicos do nosso exercício profissional com vistas à que possamos criar ou recriar instrumentos mais adequados aos indivíduos e grupos. Há necessidade de que se alcance uma clareza de quais "efeitos objetivos a atividade psicológica produz em uma determinada sociedade" (p. 13). Baró (1996), opinou que

ao assumir a conscientização como horizonte do que fazer psicológico, reconhece-se a necessária centralização da psicologia no âmbito do pessoal, mas não como terreno oposto ou alheio ao social, mas como seu correlato dialético e, portanto, incompreensível sem a sua referencia constitutiva. Não há pessoa sem família, aprendizagem sem cultura, loucura sem ordem social; portanto, não pode tampouco haver um eu sem um nós, um saber sem um sistema simbólico, uma desordem que não se remeta a normas morais e a uma normalidade social. (p. 17).

De acordo com essas idéias sobre o papel do psicólogo, será da competência dos profissionais dessa área auxiliar os indivíduos e grupos a pensarem em seus projetos de vida como possibilidades do vir-a-ser positivado que possa "contribuir para a formação de uma identidade, pessoal e coletiva, que responda às exigências mais autênticas dos povos" (Baró, 1996, p. 22).

Nesse sentido, em relação ao tema deste artigo, o objetivo principal da prática psicológica deverá ser contribuir para a construção de uma consciência acerca da realidade dos fatos que o sistema escravista deixou para a sociedade brasileira, ou seja, conhecer, explicitar e refletir sobre quais são as repercussões dessa herança nos processos de subjetivação em afrodescendentes, bem como as repercussões nas relações entre negros e não-negros, uma vez que as formas de relacionar-se foram constituídas historicamente a partir da ideologia que pregava a superioridade do branco.

Presume-se que tal empreendimento poderá ser feito primeiro pelo direcionamento da escuta para as experiências de dor, dúvida, vergonha, culpa, baixa auto-estima e tantas outras que configurem o que é nomeado como sofrimento psíquico, as quais aparecem nas escolas, nos consultórios, nas empresas, porque são resultado dos embates das relações raciais e que, em nossa sociedade, têm sido pautadas pela negativação das diferenças, produto dos antigos modos de vida que herdamos. Em segundo lugar, acredita-se que haverá avanços a partir da ocupação pelos profissionais da Psicologia desses "espaços vazios", dessa temática na academia, nos diversos exercícios profissionais, sociais e políticos, pesquisando, divulgando e propondo novas práticas que possam alcançar tanto o indivíduo quanto o coletivo nas tramas e dramas da intersubjetividade.

\section{Referências}

Andriani, A. G. (2003). A cor da pele: significações constituídas nas relações. Dissertação de Mestrado, Pontifícia Universidade Católica de São Paulo, São Paulo.

Anjos, R. S. dos (2000). Território das comunidades remanescentes de antigos quilombos. Primeira configuração espacial. Brasília: Mapas Editora \& Consultoria.

Anjos, R. S. dos (2006). Quilombolas. Tradições e cultura de resistência. São Paulo: Aori Comunicação.

Baró, I. M. (1996). O Papel do psicólogo. Estudos de Psicologia, 2(1), 7-27.

Buarque, C. (1993). A revolução das prioridades. São Paulo: Instituto de Estudos Econômicos.

Campos, A. (2005). Do quilombo à favela: a produção do "Espaço Criminalizado" no Rio de Janeiro". Rio de Janeiro Bertrand Brasil.

Carone, I. \& Bento, M. A. S. (Orgs.) (2002). Psicologia social do racismo: estudos sobre branquitude e branqueamento no Brasil. Petrópolis: Vozes.

Carvalho, J. J. (1996). O quilombo do rio das Rãs. Salvador: Editora da UFBA.

Castoriadis, C. (1982). A Instituição e o imaginário: primeira ordem. Em C. Castoriadis (Org.), A instituição imaginária da sociedade (pp. 139-198). Rio de Janeiro: Editora Paz e Terra. 
Chalhoub, S. (1996). Cidade Febril: cortiços e epidemias na Corte Imperial. São Paulo: Companhia das Letras.

Coimbra, C. M. B. (1995). Guardiães da ordem: uma viagem pelas práticas psi no Brasil do "Milagre”. Rio de Janeiro: Oficina do autor.

Coimbra, C. M. B. (2001). Operação Rio: o mito das classes perigosas- um estudo sobre a violência urbana, a mídia impressa e os discursos de segurança publica. Rio de Janeiro: Oficina do autor; Niterói: Intertexto.

Costa, F. B. da. (2004). Homens invisíveis: relatos de uma humilhação social. São Paulo: Globo.

Dorsch, F., Hacker, H. \& Stapf, K. H. (Orgs.) (2001). Dicionário de Psicologia Dorsch (E. L. Carneiro \& equipe, Trads.). Petrópolis: Vozes.

Ferreira, R. F. (2000). Afro-descendente: identidade em construção. São Paulo: EDUC; Rio de Janeiro: Pallas.

Freud, S. (1980). Psicologia de grupo e análise do ego. Em Obras completas, Volume XXIII. (C. M. Oiticica, Trad.). Rio de Janeiro: Imago. (Trabalho original publicado em 1921)

Freyre, G. (2003). Casa Grande e Senzala. São Paulo: Global. (Trabalho original publicado em 1993)

Furtado, J. F. (2003). Chica da Silva e o contratador de diamantes - o outro lado do mito. São Paulo: Companhia das Letras.

Galton, F. (1869). Hereditary genius. London: Julian Friedman.

Gobineau, A. de (1853). Essai sur l'inegalité des races humaines. Paris: Galimard-Pleiade.

Guimarães, A. S. (1999). Racismo e anti-racismo no Brasil. São Paulo: Editora 34.

Guimarães, A. S. (2002). Classes, raças e democracia. São Paulo: Editora 34.

Hasenbalg, C. (1998). Relações Raciais no Contexto Nacional e Internacional. Em C. A. Hasenbalg, K. Munanga \& L. M. Schwarcz (Orgs.), Racismo: Perspectivas para um Estudo Contextualizado da Sociedade brasileira. Estudos \& Pesquisas (pp. 9-41). Rio de Janeiro: Editora da Universidade Federal Fluminense.

Johnson, A. G. (1997). Dicionário de Sociologia: guia prático da linguagem sociológica.(R. Jungmann, Trad.). Rio de Janeiro: Jorge Zahar.

Klein, H. S. (2002). As origens africanas dos escravos brasileiros. Em S. D. J. Pena (Org.), Homo Brasilis: aspectos genéticos, lingüísticos, históricos e sociotropológicos da formação do povo brasileiro (pp. 92-112). Ribeirão Preto: FUNPEC.

Le Bon, G. (1894). Les lois psychologiques de l'e volution des peuples. Paris: S/E.

Maisonneuve, J. (1977). Introdução à Psicossociologia. (L. D. Pennas, Trad.). São Paulo: Editora da Universidade de São Paulo.

Martins, J. de S. (1997). Exclusão Social e Desigualdade. São Paulo: Editora Paulus.

Medeiros, C. A (2004). Na lei e na raça: legislação e relações raciais, Brasil-Estados Unidos. Rio de Janeiro: D. P. \& A. Editora

Meillassoux, C. (1995). Antropologia da escravidão - o ventre de ferro e dinheiro (L. Magalhães, Trad.). Rio de Janeiro: Jorge Zahar.

Moura, C. (1988). Rebeliões da Senzala-quilombos, Insurreições e guerrilhas. Porto Alegre: Mercado Aberto.

Moura, C. (1989). Quilombo: resistência ao escravismo. São Paulo: Editora Ática.

Moura, C. (Org.) (2001). Os quilombos na dinâmica social do Brasil. Maceió: EDUFAL.
Munanga, K. (1988). Negritude: usos e sentidos. Série Princípios. São Paulo: Editora Ática.

Nascimento, E. L. (2003). O sortilégio da cor: identidade, raça e gênero no Brasil. São Paulo: Editora Summus.

Neves, M. de F. R. (2002). Documentos sobre a escravidão no Brasil. Série Textos e documentos $n^{\circ}$ 6. São Paulo: Editora Contexto.

Nina Rodrigues, R. (2004). Os africanos no Brasil. Brasília: Editora da UnB. (Trabalho originalmente publicado em 1904)

Paixão, M. J. P. (2003). Desenvolvimento Humano e Relações Raciais. Rio de Janeiro: Editora D. P. \& A.

Pinaud, J. L. (1987). Insurreição negra e justiça. Rio de Janeiro: Editora EXPED.

Politzer, G. (1965). Psicologia Concreta. Buenos Aires: Jose Álvares Editor.

Reis Filho, J. T. (2000). Ninguém atravessa o arco- íris - um estudo sobre negros. São Paulo: Editora Annablume.

Reis Filho, J. T. (2005). Negritude e sofrimento psíquico. Tese de Doutorado, Pontifícia Universidade Católica de São Paulo, São Paulo.

Reis, J. J. \& Gomes, F. S. (1996). Liberdade por um fio - história dos quilombos no Brasil. São Paulo: Editora Companhia das Letras.

Reis, J. J. \& Gomes, F. S. (2003). Rebelião escrava no Brasil: a história do levante dos malês em 1835. São Paulo: Cia das Letras.

Rodrigues, J. (2000). O infame comércio: propostas e experiências no final do tráfico de africanos para o Brasil. Campinas: Editora da UNICAMP/CECULT.

Rutter, M. (1996). Resilience, concepts and findings: implications for family therapy. Journal of Family Therapy, 21, 119-44.

Santos, G. A (2002). A invenção do ser negro - um percurso das idéias que naturalizaram a inferioridade do negro. São Paulo: EDUC/FAPESP; Rio de Janeiro: Pallas.

Salles, V. (1971). O negro no Pará sob o regime da escravidão. Rio de janeiro: Fundação Getulio Vargas/UFPA.

Sawaia, B. (2001). As Artimanhas da Exclusão. Petrópolis: Editora Vozes.

Selosse, J. (1997). Adolescence, Violences et déviances (1952-1995). Paris: Éditions Matrice.

Seve, L. (1975). Marxisme et Théorie de la Personalité. Paris: Editis Sociales.

Tajfel, H. (1982). Grupos humanos e categorias sociais (L. Amâncio, Trad.). Lisboa: Livros Horizonte.

Telles, E. (2003). Racismo à brasileira: uma nova perspectiva sociológica. (A. Callado, C. Olsen \& N. M. Rodrigues, Trads.). Rio de Janeiro: Editora Relume Dumará

Vogt, C \& Fry, P. (1996). Cafundó - a África no Brasil. Campinas: UNICAMP/Cia das Letras.

Recebido em 07.03.2006

Primeira decisão editorial em 27.07.2006

Versão final em 26.02.2007

Aceito em 15.02.2007 